\title{
EL MITO DE LA SOLEDAD EN LA EDUCACION A DISTANCIA: VERDADES E INCERTIDUMBRES.
}

https://doi.org/10.29327/3860.11.20-8

Reinaldo Portal Domingo ${ }^{1}$

\section{RESUMEN}

La Educación a Distancia (EAD) en Brasil es un fenómeno rápido crecimiento y exige de sus especialistas renovada atención para garantizar un proceso de enseñanza aprendizaje con calidad. Existen diferentes preconceptos relacionados con la EAD. La mayoría de las personas con preconceptos es precisamente a causa del desconocimiento de las características de esta modalidad. Entre esos preconceptos se encuentra el mito de la soledad de los alumnos de la EAD. Intentaremos demostrar que ese mito no existe y que cuando el alumno de la EAD es atendido, utilizando todos los recursos de la EAD, su acompañamiento resulta con mayor asiduidad que el propio alumno de los cursos de la modalidad presencial.

Palabras claves: Educación a Distancia (EAD). Alumno de la EAD. Profesor/tutor de la EAD.

\section{SUMMARY}

Distance Education (EAD) in Brazil is a rapidly growing phenomenon and requires renewed attention from its specialists to ensure a quality teaching-learning process. There are different pre-concepts related to the EAD. The majority of people with preconcepts is precisely because of ignorance of the characteristics of this modality. Among these pre-concepts is the myth of the loneliness of the students of the EAD. We will try to demonstrate that this myth does not exist and that when the student of the EAD is attended, using all the resources of the EAD, his accompaniment is more frequent than the student of the pre-essential courses.

Keywords: Distance Education (EAD). Student of the EAD. Teacher / tutor of the EAD.

\footnotetext{
${ }^{1}$ Pós-doutorado pela Universidade Nacional a Distancia (UNED) do Madrid, Espanha, doutorado em Tecnologia Educativa pela Academia de Educação da Rússia . Formado em Letras pela Universidade Pedagógica de Moscou (Russia) em . Atualmente é professor titular da Universidade Federal do Maranhão, professor associado I da Universidade Federal do Maranhão. Assessor da Coordenação Pedagógica do Núcleo de Educação a Distancia da UFMA. Professor e Coordenador do Mestrado Profarte/UFMA.
} 


\section{INTRODUCCIÓN}

La Educación a Distancia (EAD) como modalidad educativa en Brasil es un fenómeno en pleno desarrollo que crece de forma exponencial. Basta observar algunas estadísticas para percibir el aumento de matrículas tanto en la educación pública, así como en la educación privada, lo que muestra la necesidad de que especialistas y profesores pongan gran atención a investigaciones y nuevos enfoques metodológicos para su perfeccionamiento actual y permanente. Hoy en día en Brasil, existen más de 1,5 millón de estudiantes que optaron por la modalidad de educación a distancia, o sea 18,6\% del total de las matrículas. En 2004, eran apenas 60 mil, 4,2\% del total general.

La cantidad de nuevos matriculados en esa modalidad, dee enseñanza superior tuvo un incremento de $21,4 \%$ de 2015 a 2016 lo que representa un $28 \%$ de los nuevos alumnos. Por otro lado, la cantidad de alumnos que entraron en plazas de la educación presencial sufrió una disminución de 3,7\% en dicho período. Una nueva inyección de alumnos fue realizada por la Universidad Abierta de Brasil (UAB) a finales de 2017 e inicios de 2018 lo que muestra claramente como esta modalidad crece a ritmos acelerados. Según Arruda (2018) el número de profesores sin título de Educación Superior que trabajan en la Educación Primaria y Básica es significativo, por lo que políticas públicas como el Programa de la UAB podría ser la solución a este gran problema de la educación brasileña.

Es bueno destacar que entre los objetivos de campaña del nuevo presidente, que tomó pose el $1^{\circ}$ de enero de 2019 se encuentra la aplicación de la modalidad a distancia a otras esferas educativas (Educación Básica y Educación de Jóvenes y Adultos - EJA) lo que traerá un gran incremento en matrículas para la modalidad de EAD.

El contenido de este artículo, que está en desarrollo desde hace algún tiempo, es el resultado de 10 años de experiencia de trabajo ininterrumpido en la modalidad, como especialista del Núcleo de Educación a Distancia (NEAD) de la Universidad Federal de Maranhão. Nos referimos en particular al mito existente (a nuestro modo de ver) sobre que el alumno de la EAD se encuentra solo y desamparado en el ciberespacio en su lucha por desarrollar un proceso de enseñanza aprendizaje de calidad dentro de la modalidad a distancia.

Trataremos de abordar un grupo de elementos y características de los alumnos, los profesores/tutores y las tecnologías de comunicación que muestran cómo nuestros alumnos de la EAD se encuentran mucho mejor acompañados y asesorados que los propios alumnos de los cursos presenciales, lo que derrumba por tierra el mito existente de que nuestros estudiantes no aprenden bien por estar abandonados a su suerte.

No es menos cierto que han existido y existen reclamaciones de alumnos que no se sienten totalmente atendidos por sus profesores/tutores, lo que a nuestro modo de ver 
no es problema de la modalidad y sí de la irresponsabilidad de algunos que no cumplen cabalmente con sus obligaciones a partir de las competencias que permanentemente el profesor/tutor debe desarrollar dentro de los parámetros de la EAD. A modo de ejemplo podemos colocar casos de profesores/tutores que deben impartir encuentros presenciales como parte del componente curricular de una asignatura por espacio de 8 (ocho) horas en un determinado Polo de Apoyo Presencial para cumplir con determinados objetivos docentes y vemos con indignación que a veces esos profesores/tutores convierten el encuentro en una "visita" de 3-4 horas sin cumplir con los objetivos planificados/estipulados que prevén contenido para 8 (ocho) horas y no para un resumen de 4 (cuatro) horas en el mejor de los casos. Sobre las recomendaciones de como corregir este problema, hablaremos más adelante.

A nuestro modo de ver para resolver el "mito de la soledad en la EAD" debemos abordar varios aspectos que están directamente relacionados con las características del alumno de la EAD, con las características y competencias del profesor/tutor de la EAD y las formas de comunicación contemporáneas que el alumno de la EAD debe saber manejar y dominar con precisión. Sobre estos temas nos referimos a continuación.

\section{DESARROLLO}

\section{EL ALUMNO DE LA EAD}

Mucho se ha hablado sobre las características de los alumnos de la EAD para poder tener un determinado éxito en su tarea de enfrentar la modalidad a distancia. Autores como Aretio (1999), Preti (1996), Belloni (2006) Palloff e Pratt (2004), Mattar (2012), Moran (2007) entre otros, nos vienen indicando cuales son las características del alumno de la EAD y cómo preparar ese discente para enfrentar la modalidad y poder alcanzar objetivos finales de suceso. Entre las características más comunes a todos los autores señalados vemos: ser flexible, saber administrar el tempo, ser organizado, le gustar de la tecnología, aprender mejor cuando se estudia solo, buscar economía para estudiar, ser pro-activo, ser o estar motivado-

En la EAD, el papel del alumno cambia de forma radical. De una actitud completamente pasiva, vestigio de la educación tradicional en la modalidad presencial, este pasa a ser el centro dentro del proceso de enseñanza aprendizaje junto con los restantes actores que participan dentro del sistema de influencias en la EAD.

Esto exige, por parte del alumno, una mayor iniciativa, autonomía y disciplina, pues él conformará su propio horario de estudio, establecerá las condiciones en las que estudiará y, dentro de límites amplios, él determinará el ritmo de estudio, adaptándolo a su perfil, posibilidades y conveniencias. 
Lo que se espera de un alumno de la EAD, es que él pueda, a partir de desarrollar habilidades de uso de las TIC, demostrar señales visibles de cambio de comportamientos, como:

- rechazo de los métodos escolares de transmisión del conocimiento en la educación de adultos;

- exigencia de retorno inmediato de información, lo que explica la receptividad a los medios interactivos;

- deseo de encontrar a otros estudiantes lo que permite comparar dificultades y discutir sobre la calidad del curso, pudiendo ocurrir de forma presencial o virtual;

- necesidad de encontrar personalmente a los tutores;

- aspiración a encontrar cursos concebidos a partir de sus necesidades específicas;

- ansiedad en relación a la evaluación y autoevaluación.

(PERRIAULT, 1996 apud BELLONI, 2001: 47).

Existen otros elementos que también consideramos importantes dentro de las características de esos alumnos de la EAD como: asumir la responsabilidad por si propio, reconocer sus puntos fuertes y limitaciones, mantenimiento y aumento de su autoestima, interacción con sus pares, esclarecimiento de lo que fue aprendido, redefinir lo que es conocimiento legítimo, lidiar con el contenido.

Se puede decir que el "talón de Aquiles" en la Educación a Distancia es la situación de aprendizaje "individual". El estudio sin la presencia regular de colegas y los profesores desafían al alumno a superar sus limitaciones personales y desarrollar su capacidad de aprender de forma autónoma, de aprender a aprender. (...) La institución pone a disposición del estudiante todo su sistema (recursos materiales y humanos, redes de comunicación) para dar soporte a su caminata. "Por otro lado, el alumno debe sumergirse, asumiendo para sí, también, la responsabilidad de su formación " (PRETI, 2000).

El cambio de la modalidad presencial donde el alumno estudió por un espacio como mínimo de 12 (doce) años, y que tiene siglos de ejecución, no es fácil de superar para pasar a esta nueva modalidad educativa de EAD.

En la educación presencial el alumno mantiene contacto permanente con su grupo, con los integrantes de su equipo de trabajo, no así con sus profesores. La ausencia de Ambientes Virtuales de Aprendizaje-AVA (en la gran mayoría de los casos) que permita dar continuidad de forma on-line a los contenidos ofertados presencialmente en clases, compromete todavía más los contactos profesor/alumnos. 
Podemos asegurar que ese alumno solo se encuentra con sus profesores en el momento de las clases (una vez a la semana cuando la asignatura es de 30 (treinta) horas, 2 (dos) veces por semana si es de 60 horas y 3 veces si la asignatura es de 90 horas), donde en ocasiones hay exceso de alumnos (más de 30) y profesores con poco tiempo para atender las necesidades particulares/ individuales de alumnos por separados, quedando fundamentalmente en un aprendizaje frontal y no en un proceso de enseñanza-aprendizaje personalizado.

Las clases en la actualidad son más de carácter frontal de corte tradicional, con pocos recursos digitales y la tenue incorporación de métodos activos; por lo que podemos presumir que esos alumnos de la modalidad presencial tienen un acompañamiento menor, por parte de sus profesores, que los alumnos de la modalidad a distancia que de hecho, si todo funciona bien, como está establecido, deben tener un acompañamiento permanente por parte del profesor/tutor (tanto a distancia como presencial) y del profesor especialista de la asignatura en cuestión.

Hay que destacar que en la actualidad los alumnos de la EAD trabajan más en equipos con tareas colaborativas que antes, logrando una presencialidad virtual mucho mayor y logrando amplios niveles de interactividad lo que garantiza un amplio intercambio de forma permanente entre alumnos/profesores/tutores, además de los encuentros presenciales establecidos del $20-30 \%$ por asignatura del currículo de los cursos.

Lamentablemente no todos los profesores implicados en la EAD conocen y aplican cabalmente lo que está establecido en la modalidad, a veces dejando mucho que desear de su actuación profesional. Esos ejemplos negativos de profesores deficientes deben ser superados, fundamentalmente con control dentro del proceso de enseñanza aprendizaje, con altos niveles de evaluación y auto-evaluación y con una formación continuada a lo largo de la vida. Quien no cumple con sus obligaciones debe ser detectado por los mecanismos de control de los cursos y sustituidos, hasta que supere los errores cometidos en su desempeño.

A continuación nos referiremos a las características del profesor para garantizar ese acompañamiento permanente del alumno en la EAD y la ruptura del mito de la soledad.

\section{EL PROFESOR/TUTOR DE LA EAD}

Moran (2007) entiende que entre las principales tareas del profesor hoy, el papel principal es ayudar al alumno a interpretar los datos e imágenes recibidas y relacionarlas y contextualizarlas, pues la adquisición del conocimiento dependerá cada vez menos del profesor: las tecnologías son quien se encargarán de ello. Su papel es, sobre todo, 
"movilizar el deseo de aprender, para que el alumno se sienta siempre con ganas de conocer más" (página 33).

En la era del conocimiento el profesor dejó de ser el dueño de la verdad y pasa a ser el organizador, el "coach", como bien dice Pedro Demo, el incentivador de realizar un proceso de enseñanza aprendizaje desarrollador con un marcado uso de las tecnologías contemporáneas.

Los Referenciales de Calidad para la Educación Superior a Distancia distingue entre las tutorías: La tutoría a distancia que actúa desde la institución, mediando el proceso pedagógico junto a estudiantes geográficamente distantes, y referenciados a los polos descentralizados de apoyo presencial (MEEC / SEED, 2007, p. 21).

Por lo tanto, su principal atribución consiste en:

[...] aclaración de dudas a través de foros de discusión por Internet, por teléfono, participación en videoconferencias, entre otros, de acuerdo con el proyecto pedagógico [...] seleccionar material de apoyo y la sustentación teórica a los contenidos y, a menudo, forma parte de sus atribuciones participar en los procesos de evaluación de la enseñanza-aprendizaje, junto con los docentes. (MEEC / SEED, 2007, página 21).

Los tutores presenciales actúan en cada polo con las siguientes tareas:

- Servir como eslabón de comunicación entre, por un lado, los estudiantes, y de otro, profesores formadores y coordinación del curso;

- Incentivar y motivar el trabajo colaborativo y cooperativo, formando grupos de estudio entre los estudiantes;

- Coordinar las actividades académicas desarrolladas en y en el caso de que se trate de una persona,

- Acompañar la frecuencia de los estudiantes en el polo y recoger información sobre el proceso de aprendizaje;

- Acceder diariamente el ambiente de enseñanza-aprendizaje adoptado por el curso.

Somos de la opinión que además de las tareas mencionadas tanto el tutor a distancia como el presencial deben incentivar y apoyar los procesos de investigación que como eje transversal deben ser realizados en todos los cursos de la modalidad a distancia. Este es un eslabón relativamente débil que debe ser reforzado por los profesores/tutores para que nuestros alumnos asimilen la investigación como herramienta de trabajo permanente en todas las asignaturas del currículo. (Domingo 2018). 
Para finalizar, queremos destacar que aquellos profesores/tutores que cumplan cabalmente con sus tareas específicas, estipuladas por la modalidad a distancia (tanto las on-line como las presenciales) desarrollarán un acompañamiento permanente de sus alumnos para que sin duda alguna ese alumno no se sienta desorientado y tenga la información suficiente y necesaria para cumplir con sus tareas y aprender con los requisitos de calidad esperados por todos. Estos son los profesores que necesitamos y aspiramos tener hoy y siempre. “esos son los imprescindibles” Bertolt Brecht. ${ }^{2}$

\section{LA COMUNICACION DEL ALUMNO DENTRO DE LA MODALIDAD A DISTANCIA/EAD}

En ambientes virtuales de educación, que es el caso de la EAD, el papel del alumno y del profesor cambia y vemos que el foco no está más en la transmisión de informaciones, sino en la construcción de conocimientos propiciados a partir del diálogo, de la interacción y del intercambio de experiencias, resultando en la creación de ambientes colaborativos de aprendizaje.

La educación es un proceso de comunicación por excelencia, que en la EAD ocurre no sólo en la forma de encuentro físico presencial, sino, sobre todo, en función de la distancia, a través de los medios tecnológicos contemporáneos. Así, ese encuentro implica una suspensión de la distancia, ya sea espacial o temporal, pero no una supresión de la distancia. Esto significa decir que quien es responsable por la eliminación de la distancia es la tecnología, capaz de construir interacciones en diferentes situaciones.

Recordando que la suspensión significa hacer parar, interrumpir temporalmente, y supresión significa eliminar, cortar. De esta forma, las tecnologías eliminan la distancia.

En la actualidad con el uso coherente de las TIC los flujos de comunicación son permanentes e instantáneos, o como bien dicen: a un clik. Por lo tanto, la comunicación debe ser bidireccional, con diferentes vías de acceso, ida y vuelta. La actividad educativa, como proceso de comunicación, debe tener la retroalimentación entre docente y alumno. El diálogo consubstancia, así, la optimización del acto educativo. La bidireccionalidad es una forma de comunicación que está concebida para el emisor y el receptor, y sucede cuando todo emisor es potencialmente un receptor, y viceversa. En este caso la EAD rompe la tradición de uno a muchos y establece el mecanismo de muchos a muchos, logrando una educación colaborativa de amplia interactividad. La

\footnotetext{
2 “Hay hombres que luchan un día y son buenos. Hay otros que luchan un año y son mejores. Hay quienes luchan muchos años, y son muy buenos. Pero los hay que luchan toda la vida: esos son los imprescindibles." Bertolt Brecht
} 
interacción y la interactividad se vuelven imperativos en ese momento, determinando actitudes de reflexión-acción de la práctica educativa.

Dentro de esta dinámica el alumno puede responder a cuestiones que le son propuestas en los materiales didácticos, así como puede establecer diálogos con su profesor/tutor, enriqueciendo su actividad de aprendizaje y eliminando el mito de la soledad dentro de la EAD.

Actualmente, para satisfacer las exigencias de calidad del proceso pedagógico, deben ofrecerse modernas condiciones de telecomunicación y telemática. Estos canales de comunicación deben ser constantemente utilizados, con la intención de generar un sistema por el que los alumnos, tutores, profesores y la institución puedan comunicarse entre sí, posibilitando un sistema eficaz de distribución y mantenimiento de los niveles informáticos y comunicativos.

La EAD utiliza y debe utilizarse de las TIC para viabilizar la comunicación entre todos los actores del proceso de enseñanza/aprendizaje. La interacción y la interactividad se vuelven imperativos en ese momento, determinando actitudes de reflexión-acción de la práctica educativa.

Esta modalidad evolucionó y pasó a tener una nueva "cara", en la medida que se han ido perfeccionado las tecnologías, aumentando sobre todo las posibilidades de aplicación de mediadores del aprendizaje, del material impreso a los ambientes virtuales de aprendizaje, de los Correos a la Web 3.0.

Cabe destacar que los alumnos ingresantes hoy en la EAD poseen habilidades informáticas superiores a la de los alumnos de 5-10 años atrás. Hoy se observa un incremento en cuanto al uso de celulares, tabletas y computadores en función de la docencia y la investigación, lo que coloca el proceso de enseñanza/aprendizaje en mejores condiciones de éxito.

A partir de lo antes expresado, vemos como nuestros alumnos de la EAD que cumplen cabalmente con sus obligaciones, son cada día más participativos, exigentes consigo mismos y con sus colegas y profesores, conscientes de la necesidad de cumplir con las tareas docentes con calidad en su condición de alumnos autores (desterrando el plagio de su forma de actuar) y manteniendo altos niveles de comunicación entre sus pares y con sus profesores tutores tanto a distancia como presenciales con amplio uso de la tecnología disponible.

\section{CONSIDERACIONES FINALES}

En este trabajo hemos tratado de mostrar como la EAD hoy es un fenómeno en crecimiento tanto en las universidades públicas como en las privadas de todo Brasil, tratando de alcanzar altos estándares de calidad para garantizar que la modalidad 
continúe en aumento y que los alumnos se identifiquen cada vez más con la EAD a partir de sus potencialidades y satisfacciones.

No es menos cierto que todavía existen retos importantes, tanto tecnológicos como docentes para garantizar un proceso de enseñanza/aprendizaje a la altura del siglo XXI, donde la conectividad permita efectivos niveles de comunicación entre todos los participantes y el uso extensivo de la videoconferencia como momento presencial a distancia, la incorporación paulatina y permanente de los últimos avances en cuanto a materiales docentes digitales (e-book, objetos de aprendizaje, video-aulas, realidad ampliada, simuladores, entre otros). Todo esto mantendrá al alumno, sin dudas, dentro de procesos de comunicación permanentes, lo que tira por tierra el mito, el preconcepto de la soledad del estudiante actual de la EAD.

Cuando todos los actores participantes del proceso de enseñanza aprendizaje de la modalidad a distancia cumplen con calidad sus obligaciones queda evidenciado que el alumno aprende y aprende bien y este no se siente solo ni desamparado en ningún momento del proceso, todo lo contrario se transforma en un alumno participativo, colaborativo, investigativo que busca en todo momento interacción con sus colegas para la construcción individual del conocimiento, aprovechando al máximo todas las herramientas tecnológicas y humanas en el desarrollo de un proceso que tira por tierra el mito de la soledad en la EAD.

\section{REFERENCIAS}

ALVES, Lynn; NOVA, Cristiane. Educação a distância: uma nova concepção deaprendizado e interatividade, Ed. São Paulo: Futura, 2003.

ARETIO, García. Educación a distancia hoy. Madrid: UNED, 1999.

ARRUDA, Eucidio Pimenta. Dimensões da formação de professores como argumento para a constituição do Sistema Universidade Aberto do Brasil nas instituições públicas de ensino superior. Santa Maria I v.431 n, 41 p. 823-842 Educação. 2018

BELLONI, Maria Luiza. Educação a Distância. 4ta.ed.São Paulo: Autores associados, 2003. 
BRECHT. Bertolt. https://www.levante-emv.com/blogs/el-sonido-del-silencio-sds/poesia-unos-versos-de-bertolt-brecht.html

BIELSCHOWSKY Carlos. Qualidade na Educação Superior a Distância no Brasil: Onde Estamos, para Onde Vamos? http://eademfoco.cecierj.edu.br/index.php/Revista/article/view/709/284.

DOMINGO Portal Reinaldo. La Investigación en los cursos de licenciatura de la modalidad a distancia: actualidad $y$ futuro en el ejemplo de la UFMA. EDUCAÇÃO \& LINGUAGEM (ONLINE), v. v. 21, p. 109-119, 2018.

MATTAR, João. Tutoria e interação em educação a distância. São Paulo: Cengage Learning, 2012.

MORAN, José M. A educação que desejamos: novos desafios e como chegar lá. Campinas, SP: Papirus, 2007

PALLOFF, Rena M; PRATT, Keith. O Aluno Virtual: um guia para trabalhar com estudantes on-line. Porto Alegre: Artmed, 2004.

PRETI, Oreste. Educação a Distância: construindo significados. Cuiabá: NEAD/IE UFMT; Brasília: Plano, 2000.

PRETI, Oreste. Educação a distância: uma prática educativa mediadora e mediatizada. In: PRETI, Oreste (org). Educação a distância: início e indícios de um percurso. Cuiabá: UFMT, 1996.

REFERENCIAIS DE QUALIDADE DA EDUCAÇÃO SUPERIOR A DISTANCIA. http://portal.mec.gov.br/seed/arquivos/pdf/legislacao/refead1.pdf 


\section{Reinaldo Portal Domingo}

Pós-doutorado pela Universidade Nacional a Distancia (UNED) do Madrid, Espanha , doutorado em Tecnologia Educativa pela Academia de Educação da Rússia . Formado em Letras pela Universidade Pedagógica de Moscou (Russia) em . Atualmente é professor titular da Universidade Federal do Maranhão, professor associado I da Universidade Federal do Maranhão. Assessor da Coordenação Pedagógica do Núcleo de Educação a Distancia da UFMA. Professor e Coordenador do Mestrado Profarte/UFMA.

\section{Artigo recebido em 17/12/2018 \\ Aceito para publicação em 30/07/2019}

\section{Para citar este trabalho:}

DOMINGO, Reinaldo Portal.EL MITO DE LA SOLEDAD EN LA EDUCACION A DISTANCIA: VERDADES E INCERTIDUMBRES. Revista Paidéi@. Unimes Virtual. Volume 11- Número20 - JULHO - 2019 - Disponível em: 